\title{
The use of mobile applications in higher education classes: a comparative pilot study of the students' perceptions and real usage
}

David Manuel Duarte Oliveira* (D), Luís Pedro and Carlos Santos

* Correspondence: david.oliveira@ ua.pt

Communication and Arts Department, Universidade de Aveiro, Campus Universitário de Santiago, 3810-193 Aveiro, Portugal

\begin{abstract}
This paper was developed within the scope of a PhD thesis that intends to characterize the use of mobile applications by the students of the University of Aveiro during class time. The main purpose of this paper is to present the results of an initial pilot study that aimed to fine-tune data collection methods in order to gather data that reflected the practices of the use of mobile applications by students in a higher education institution during classes. In this paper we present the context of the pilot, its technological settings, the analysed cases and the discussion and conclusions carried out to gather mobile applications usage data logs from students of an undergraduate degree on Communication Technologies.

Our study gathered data from 77 participants, taking theoretical classes in the Department of Communication and Arts at the University of Aveiro. The research was based on the Grounded Theory method approach aiming to analyse the logs from the access points of the University. With the collected data, a profile of the use of mobile devices during classes was drawn.

The preliminary findings suggest that the use of apps during the theoretical classes of the Department of Communication and Art is quite high and that the most used apps are Social networks like Facebook and Instagram. During this pilot the accesses during theoretical classes corresponded to approximately 11,177 accesses per student. We also concluded that the students agree that accessing applications can distract them during these classes and that they have a misperception about their use of online applications during classes, as the usage time is, in fact, more intensive than what participants reported.
\end{abstract}

Keywords: Mobile application, Mobile usage, Higher education, Classes, Logs (c) The Author(s). 2021 Open Access This article is licensed under a Creative Commons Attribution 4.0 International License, which permits use, sharing, adaptation, distribution and reproduction in any medium or format, as long as you give appropriate credit to the original author(s) and the source, provide a link to the Creative Commons licence, and indicate if changes were made. The images or other third party material in this article are included in the article's Creative Commons licence, unless indicated otherwise in a credit line to the material. If material is not included in the article's Creative Commons licence and your intended use is not permitted by statutory regulation or exceeds the permitted use, you will need to obtain permission directly from the copyright holder. To view a copy of this licence, visit http://creativecommons.org/licenses/by/4.0/. 


\section{Introduction}

The use of mobile devices by higher education students has grown in the last years (GMI, 2019). Technological advancements are also pushing society with consequent rapidly changing environments. Higher Education Institutions (HEIs) are not exempted from these technological changes and advancements, and it is compulsory that they follow this technological evolution so that the teaching-learning process is improved and enriched.

HEI's are trying to integrate digital devices such as mobile phones and tablets, and informal learning situations, assuming that the use of these technologies may result in a different learning approach and increase students' motivation and proficiency (Aagaard, 2015).

In a study by Magda, \& Aslanian (2018), students report that they access course documents and communicate with the faculty via their mobile devices, such as smartphones. Over $40 \%$ say they perform searches for reports and access institutions ELearning systems via mobile devices (Magda, \& Aslanian, 2018). The EDUCAUSE Horizon Report - 2019 Higher Education Edition (Alexander et al., 2019) also mentions M-Learning as the main development in the use of technology in higher education. However, teachers believe students use their gadgets less than they actually do, and mobile devices also challenge teaching practices. Students use devices for off-task (Jesse, 2015) or parallel activities and there may be inaccurate references to their actual use of mobile devices.

Mobile device users have very different usage habits of their devices and their applications, and it is important to study and characterize these behaviours in different contexts, as explained below. The reports that usually support these studies are made with questions directed to the users themselves asking them questions about the apps they have on the devices and the reasons for using them. However, Gerpott \& Thomas (2014) argue that other types of studies are needed to properly support this type of research.

Studies are usually conducted in organizations, based on the opinion of the participants, and cannot be replicated and generalized, for example, regarding the use of the internet or mobile applications by the general public, because these devices, unlike desktop devices, can be used anywhere and at any time (Gerpott \& Thomas,2014).

Furthermore, in mobile contexts, it becomes difficult for people to remember what they have used, because mobile applications can be used for various tasks, in various contexts, whether professional or personal, and the variety of applications, the use made, the periods of use are usually so wide and differentiated, that it can become difficult for users to refer which services or applications they have used, under which circumstances and how often. (Boase \& Ling, 2013).

Thus, it is relevant, for several areas and especially for this research area, to have studies that cross-reference reported usage with actual usage. One of the ways to achieve this is with the use of logs of the use of mobile devices and applications, as mentioned by De Reuver \& Bouwman (2015):

Using this approach this pilot study aims to create and validate a methodology:

i) to show the profile of these users,

ii) to reveal the kind of applications they use in the classroom and when they are in the institutions, 
iii) and also, to compare the users' perceptions with the real use of mobile applications.

Knowing the real usage and the usage students mention may provide valuable insights to teachers and HEIs and use this data for decision making about institutional applications to support students and teachers in their teaching and learning activities. Such information can also bring insights on the integration of M-Learning strategies, promoting interaction, communication, access to courses and the completion of assignments using students' devices.

The central focus of this study is, therefore, to show preliminary results of the use of applications by students in class time during theoretical classes, through logs collected during class time.

The paper is divided into five parts. In the first part, relevant theoretical considerations are addressed, having in mind the current state of the art in terms of the literature and empirical work in this field. The second part outlines the study methodology. In the third part, the technological setting is highlighted. The cases and the results of the data analysis are described in the fourth part. Lastly, the results are interpreted, connected and crossed with the preliminary considerations.

\section{Literature review}

The massive use of mobile devices has created new forms of social interaction, significantly reducing the spatial difficulties that could exist, and today people can be reached and connected anytime and anywhere (Monteiro et al., 2017). This also applies to the school environment, where students bring small devices (smartphones, tablets and ebook readers) with them, which, thanks to easy access to an Internet connection, keep them permanently connected, even during classes.

In HEIs there is also a growing tendency among members of the academic community to use mobile devices in their daily activities (Oliveira et al., 2017), and students expect these devices to be an integral part of their academic tasks, too (Dobbin et al., 2011). A great number of users take advantage of mobile devices to search information and, since they do not always have computers available, these devices allow them an easy access to academic and institutional information (Vicente, 2013).

One of the challenges educational institutions face today has to do with the ubiquitous character of these devices and with finding ways in which they can be useful for learning, thus approaching a new educational paradigm: Mobile Learning (M-Learning) (Ryu \& Parsons, 2008).

M-learning allows learning to take place in multiple places, in several ways and when the learner wants to learn. As learning does not necessarily have to occur within school buildings and schedules, M-Learning reduces the limitations of learning confined to the classroom (Sharples, M., Corlett, D. \& Westmancott, 2002), leading UNESCO to consider that M-Learning, in fact, increases the reach of education and may promote equality in education (UNESCO, 2013). The EDUCAUSE Horizon Report - 2019 Higher Education Edition (Alexander et al., 2019) also mentions M-Learning as the main development in the use of technology in higher education and, therefore, it becomes increasingly relevant to rethink learning spaces in a more open perspective, both physically and methodologically, namely through mobile learning that places the student at the centre of the learning process. 
Quite often studies that intend to determine the use of mobile applications focus on general questions, but the most common ones are related to the frequency and duration of the use of these devices, for example, questions such as "how many SMS or calls are made?" or "how often do you use the device?"

In fact, instruments like questionnaires are widely used in this type of studies. However, since mobile devices are completely integrated in our daily life and we use them quite extensively, it is difficult to retain and define with plausible accuracy the actual use that we make of them.

It is therefore relevant to effectively understand how these students use these devices, more specifically the applications installed on them. To this end, most studies have been based on designs that are focused on the users' perceptions and based are on these reports.

Thus, it was important to understand if what users report using corresponds to what they actually use, and if this use does not occur for distraction or entertainment, for example.

Considering the above, some studies have focused on the validity of the use of these instruments. One of these first studies, carried out by Parslow et al. (2003), aimed at determining the number of calls made and received in the days, weeks or months preceding the date of the questionnaire, and their duration. The answers were compared with the logs of the operators and it was concluded that self-report questionnaires do not always represent the actual pattern of use.

Finally, in self-report instruments, which refer to questions of daily activity on mobile devices, this activity may not represent a general pattern of activity, since from individual to individual the patterns of daily use may vary considerably and thus reflect a very irregular use.

In a study by Boase \& Ling (2013), the authors mentioned that about $40 \%$ of studies on mobile device use, based on articles published in journals (41 articles between 2003 and 2010), are based on questionnaires.

The questions asked aim to estimate how long or what type of use they have made of their devices on a daily basis, and sometimes aim to know about time periods of several days. In most of these studies, $40 \%$ of papers use at least one measure of frequency of use and $27 \%$ a measure of duration of use that users make. Another factor that is mentioned is that users do not always report their usage completely accurately. On the other hand, the same study mentions that users may over or under report the use they make for reasons of sociability (Boase \& Ling, 2013).

Given the moderate correlation between self-report instruments and data from records or logs (Boase \& Ling, 2013), the author considers that researchers can significantly improve the results if they use, together with other instruments, data from logs to make their studies more accurate and rigorous. Another suggestion would be the use of mobile applications that record these usage behaviours (Raento et al., 2009).

Indeed, this kind of instrument is widely used in this type of studies. However, given that mobile devices are fully integrated into our daily lives and we use them quite extensively, it becomes difficult to retain and define with plausible accuracy the use we make of them. In addition to the factors mentioned in the previous paragraph, it is important that these types of studies are validated with other methods, such as the use of 
logs, as presented in this study. The logs in this study refer to the capture records of the mobile device traffic made by the students.

This article therefore aims to present preliminary results with an approach that uses cross-checking of log data with questionnaire results.

\section{Methodology}

This article intends to present and discuss preliminary results of a study that aims to characterize the use of mobile applications at the University of Aveiro through collected logs, crossing its results with questionnaires answered by students during the classes, and also with an observation grid with data from the analysed class and questions to teachers related to what teachers recommend regarding the use of mobile phones during class time.

The research question that motivated this article is: which digital applications/services are most frequently used on mobile devices by the students of the University of Aveiro during their classes?

The study was composed of 40 students, that answered the questionnaires.

The research was based on the Grounded Theory method aiming to analyse the logs from the access points of the University. With the collected data, a usage profile of mobile devices during classes was drawn.

Figure 1 presents a diagrammatic representation of the created methodological process.

Therefore 3 instruments were used for the data collection: a questionnaire, an observation grid and logs collected through mobile traffic in the wi-fi network of the university.

The questionnaire allowed for a quantitative assessment of the profile of the participants and collected data on the use that participants claimed to make of their mobile devices. The observation grid served as a guide for the implementation of the study, allowing to record data on the classes where the collections took place and to verify whether certain items were present, such as permission to use mobile devices or planning to use them by teachers. The observation grid would also serve to make the link between use and content in class, but in this pilot, it was not possible to make this link between the class content and the usage of mobile applications, because the author could not observe the applications used by students.

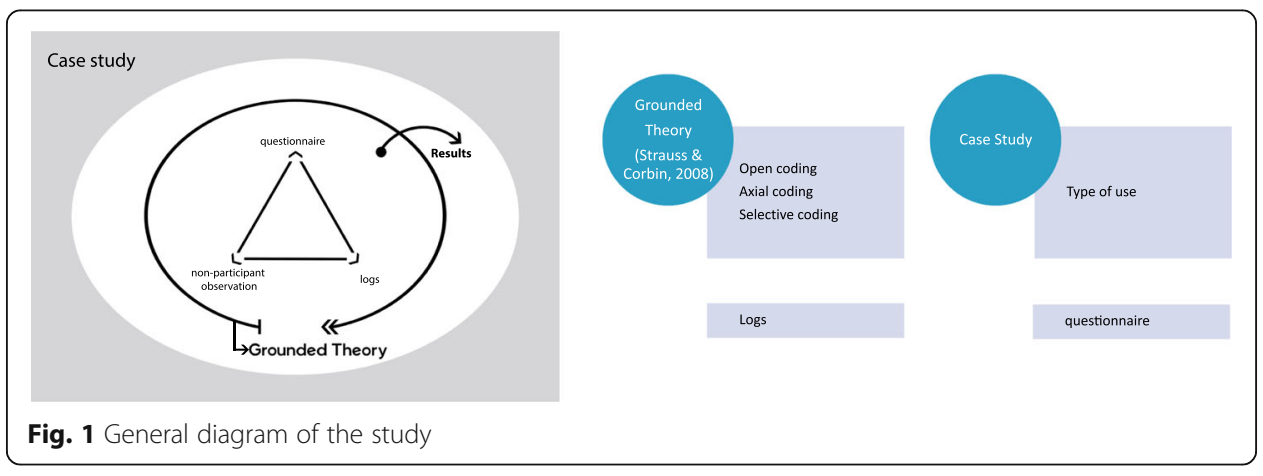


The database containing the usage records enabled the analysis of the logs, resulting in the quantification and verification of the type of activity that each (anonymous) participant made of their device.

The 3 instruments used aimed to i) determine which application(s) students were really using during the classes, through the analysis of the data logs collected from the Wi-Fi network of the University; ii) identify the participants' representations of their activities by means of several questions regarding mobile usage during class time; iii) observe students' behaviour and focus via an observation grid that was used by the researcher/observer when he was attending the classes.

The group who participated in this pilot study was selected in accordance with the professors and classes available, so it is considered a convenience sample. The group was constituted by students of undergraduate classes from the Communication and Arts Department of the University of Aveiro.

Table 1 summarizes the schedule of the pilots carried out, the curricular units where they took place, their duration and the instruments used. For ease of management, all the pilots took place in the same department of the University.

The Table 2 summarizes the collected data from questionnaires and logs.

This pilot aimed to build an approach to data analysis, close to the Grounded Theory methodology, in which a provisional theory is built based on the observed and analysed data (Alves et al., 2017; Long et al., 1993). The data collected in this pilot will serve to define a more complete methodology to be used in a larger study.

\section{Results}

This chapter is divided into three parts: context, technological setting and cases analysed. In the context part, the classes which are part of the study will be described, relating the answers from the questionnaires with the teachers' recommendations about the use of mobile devices. In the technological scenario section, it is intended to describe the technological background underlying the collection process of the logs and in the last part, analysed cases, the objective was to validate if the data to be collected matched the outlined objectives.

\section{Context}

In the questionnaire, the questions were divided into two main groups: aspects related to the participant's profile and aspects directly related to the use of the applications.

Table 1 Schedule of pilots

\begin{tabular}{|c|c|c|c|c|c|c|}
\hline \multicolumn{7}{|l|}{ Pilots } \\
\hline Pilots & Department & Class & Duration & Date & $\begin{array}{l}\mathrm{N} .^{\circ} \\
\text { Students }\end{array}$ & Instruments \\
\hline Pilot 1 & - & - & $2 \mathrm{~h}$ & - & $\begin{array}{l}2 \\
\text { Students }\end{array}$ & Logs \\
\hline Pilot 2 & DeCA & Aesthetics & $1 \mathrm{~h}$ & $\begin{array}{l}07-12- \\
16\end{array}$ & $\begin{array}{l}34 \\
\text { Students }\end{array}$ & Logs / observation grid \\
\hline Pilot 3 & DeCA & Scriptwriting & $1 \mathrm{~h}$ & $\begin{array}{l}11-04- \\
17\end{array}$ & $\begin{array}{l}22 \\
\text { Students }\end{array}$ & Logs / observation grid \\
\hline $\begin{array}{l}\text { Final } \\
\text { Pilot }\end{array}$ & DeCA & $\begin{array}{l}\text { Music in History and } \\
\text { Culture }\end{array}$ & $1 \mathrm{~h}$ & $\begin{array}{l}12-04- \\
18\end{array}$ & $\begin{array}{l}2 \\
\text { Students }\end{array}$ & $\begin{array}{l}\text { Logs / observation grid / } \\
\text { questionnaire }\end{array}$ \\
\hline
\end{tabular}


Table 2 Summary of data collection

\begin{tabular}{llll}
\hline Class & $\begin{array}{l}\mathbf{N}^{\circ} \text { Students in } \\
\text { class }\end{array}$ & $\begin{array}{l}\mathbf{N}^{\circ} \text { Answers in } \\
\text { questionnaires }\end{array}$ & $\begin{array}{l}\mathbf{N}^{\circ} \text { of students with data in } \\
\text { logs }\end{array}$ \\
\hline Aesthetics & 44 & 19 & 35 \\
Scriptwriting & 36 & 9 & 30 \\
$\begin{array}{l}\text { Music in History and } \\
\text { Culture }\end{array}$ & 16 & 12 & 12 \\
\hline
\end{tabular}

Aspects related to participants were intended to characterize them. Regarding the use of applications, we aimed to find out the students' perception of the applications they use in their daily routine, inside and outside of the classroom, and how they do it. Data were collected using a Google Forms form and processed using Microsoft Excel.

In this subchapter, through the data collected from the students' answers to the questionnaires, and by crossing this information with the data collected from the teachers in the observation grid, we try to describe the context of the pilot.

All of the teachers stated that they allowed their students to use mobile phones during class time, but that they did not plan that use. They also stated that in most part of the classes several students use their mobile phones and apps to search for class related materials. The teachers also showed curiosity about knowing, with more detail, the mobile phone use their students actually have.

In the three classes analysed (Aesthetics, Scriptwriting and Music in History and Culture), when asked about the possibility of using mobile applications as a pedagogical complementary resource $43 \%, 47 \%$ and $55 \%$ of students fully agreed that these should be used. In these three classes, $31 \%, 44 \%$, and $67 \%$ of students showed a more moderate opinion: they agreed (but not in such an assertive way) that these should be used.

Another conclusion is that most of the students used a smartphone $(88,9 \%, 75 \%$, $52 \%)$ during class time, but many of them also used a computer $(66,7 \%, 100 \%, 84 \%)$. The percentage use of tablets is much lower $(11,1 \%, 0 \%, 15 \%)$.

In the analysed scenario, the majority of the students used the android operating system and $94 \%$ also agreed that mobile applications could help to manage the academic tasks, except in the case of the "Aesthetics Curricular Unit".

When it comes to the time of use, per week, in classes, $53 \%, 58 \%$, and $22 \%$ of the students answered they used these devices between 4 to 5 days a week and $15 \%, 40 \%$ and $70 \%$ said they used them between 1 to 3 days a week.

Students were also asked about how frequently they accessed mobile applications during class time and, in all, 77\% of the respondents reported accessing apps at least between 1 to 5 times per class. About 20\% referred they accessed apps from 6 to 10 times per class.

As for the purposes of accessing apps during classes, most students mentioned categories related i) to support the class / to research $(70 \%, 100 \%, 77,8 \%)$, ii) to access institutional platforms $(47.4 \%, 66.7 \%, 89,9 \%)$, iii) to access to information $(47.4 \%, 50 \%$, $66.7 \%)$ and iv) to work (36.8\%, 50\%, 44.4\%).

Interestingly, the categories communication $(52.6 \%, 41.7 \%, 22.3 \%)$, collaboration $(10.5 \%, 16.7 \%, 0 \%)$, access to institutional services $(5.3 \%, 0 \% 0 \%)$ and "I do not use them" $(10.5 \%, 0 \%, 0 \%)$ presented very low percentages, namely the last one.

When questioned about the use of mobile devices that did not include academic reasons, many students referred to the categories "to be linked/connected" or "to be 
updated" (42.1\%, 66.7\%, 33.3\%), "to communicate" (57.7\% 75.7\%, 66.7\%), "to share and access content" (31.6\%, 58.3\%, 33.3\%), but few mentioned "for entertainment" (26.3\%, $16.7 \%, 22.2 \%)$, "as a habit or routine" $(10.5 \%, 41.7 \%, 11.1 \%)$ and "I do not use them" (10.5\%, 0\%, 11.1\%).

When asked about which mobile applications are most used in an academic context, the most relevant category was "to research / to study" (73.7\%, 58.3\%, 89.9\%), "to check the calendar" (31.6\%, 25\%, 66.7\% \%) and "to surf the web" $(47.4 \%, 50 \%$, $55.6 \%)$. Again, categories such as "to work" (36.8\%, 33.3\%, 33.3\%), "to take notes" $(26,2 \%, 33.3 \%, 55.6 \%)$ and "to create content" $(31.6 \%, 25 \%, 11.1 \%)$ presented relatively low percentages. It should also be noted that the respondents presented answers that created categories which were not expected such as "to watch films" $(10.5 \%, 8.3 \%, 0 \%)$, "to listen to music" $(31.6 \%, 33.3 \%, 33.3 \%)$, "to take photos" $(10.5 \%, 0 \%, 0 \%)$ and "to play games" $(5.3 \%, 0 \%, 0 \%)$ All the students said that they used applications during classes in at least one of the categories. In fact, in the three courses no one stated "not to use them" ( $0 \%$ in all).

When asked about the teachers' permission to use the mobile devices in the classroom, most of the students said that teachers allowed free use (52.6\%, 100\%, 77.8\%). Only a few stated that teachers allowed using them specifically when planned $(41,1 \%$, $0 \%, 22.2 \%)$. The respondents of one course stated that teachers did not allow the use of devices (Aesthetics - 5.3\%). Finally, when asked about the usefulness of integrating mobile applications in class, there was an overwhelming majority of respondents $(100 \%$, $78,9 \%, 100 \%)$ saying they believed that such integration could be enriching and useful.

Below is presented a table describing the most used mobile apps during class activities. It should be noted that only the two answers with the greatest relevance for each category were considered.

Table 3 systematizes what the results have been showing until now: there is an important part of students that use mobile phones during their classes and, even when teachers advise them not to use them, they ignore the recommendations and use them anyway. The main purposes stated were: to be in contact with others through social networking but also to access different kinds of information in browsers. Moreover, the classes where the use of devices is not recommended by the teachers seems to be the one where some applications are most used.

\section{Technological setting}

In this section we intend to describe the technological background underlying the process of collecting the logs. The first goal was to register and capture logs from the wi-fi network of the university, which consists of a wireless network that users can access using their universal user credentials.

In order to do that a meeting was scheduled with the university's technology services, as our main concern was the anonymization of the data collected in order (i) to confer more neutrality to the data treatment, and (ii) to comply with European data protection legislation. Another issue for discussion was the need of powerful machines so that they could process the large amount of data collected.

In this meeting the necessary steps were agreed in order to guarantee the users' privacy, the authorization of the university's central services to do the study and the 
Table 3 Application data usage

\begin{tabular}{|c|c|c|c|c|}
\hline & & \multicolumn{3}{|c|}{$\%$ of Use in each Class } \\
\hline & & "Aesthetics" & "Scriptwriting" & "Music in History and Culture" \\
\hline \multirow[t]{2}{*}{ Chat } & Messenger & $89 \%$ & $100 \%$ & $100 \%$ \\
\hline & Whatsapp & $26 \%$ & $25 \%$ & $22 \%$ \\
\hline \multirow[t]{2}{*}{ Browser } & Chrome & $89 \%$ & $100 \%$ & $66 \%$ \\
\hline & Safari & $21 \%$ & $33 \%$ & $33 \%$ \\
\hline \multirow[t]{2}{*}{ Videoconference } & Messenger & $36 \%$ & $66 \%$ & $77 \%$ \\
\hline & Skype & $31 \%$ & $25 \%$ & $22 \%$ \\
\hline \multirow[t]{2}{*}{ Social network } & Facebook & $73 \%$ & $100 \%$ & $66 \%$ \\
\hline & Instagram & $63 \%$ & $100 \%$ & $77 \%$ \\
\hline \multirow[t]{2}{*}{ E-mail } & Gmail & $73 \%$ & $66 \%$ & $89 \%$ \\
\hline & Outlook & $57 \%$ & $75 \%$ & $66 \%$ \\
\hline \multirow[t]{3}{*}{ Vídeo } & Youtube & $89 \%$ & $100 \%$ & $100 \%$ \\
\hline & Vimeo & $10 \%$ & $16 \%$ & $11 \%$ \\
\hline & Netflix & $5 \%$ & $8 \%$ & $22 \%$ \\
\hline \multirow[t]{2}{*}{ Music } & Spotify & $63 \%$ & $75 \%$ & $77 \%$ \\
\hline & Apple music & $21 \%$ & $0 \%$ & $11 \%$ \\
\hline \multirow[t]{2}{*}{ Photography } & Instagram & $78 \%$ & $100 \%$ & $77 \%$ \\
\hline & Camara native & $31 \%$ & $58 \%$ & $77 \%$ \\
\hline
\end{tabular}

registration method of the logs. The overall procedure demanded several experiences of data collection to fine-tune the final pilot, which works as the basis capture setting for all the main study.

The Wi-Fi traffic capture software (Wireshark) was selected to work both with Android and IOS devices and it was possible to understand the functionalities of the software.

The pilot also helped to understand and solve additional problems that appeared during the previous tests, related to the anonymization of the users' data. It was necessary to ensure that the users' personal data were not identifiable, which was a commitment: in fact, only HTTPS ${ }^{1}$ traffic was captured, being all the other information encrypted.

After the first tests, an initial data collection pilot took place in a classroom context. A specific capture system was created to allow the capture of mobile application logs used only by a certain group of students, from a designated Curricular Unit. A specific scenario was set up to ensure that only those students communicating through the $\mathrm{IP}^{2}$ defined for the scenario and during that class time were considered and treated under the scope of this study:

- If the traffic of the concerned student is communicating through one of the APs (Access Points) covering the room, then the device will be assigned a "Room network" IP;

\footnotetext{
${ }^{1}$ HTTPS It is a protocol used for secure communication over a computer network, and is widely used on the Internet

${ }^{2} \mathrm{IP}$ is the $\mathrm{s}$ a numerical label assigned to each device connected to a computer network that uses the Internet Protocol for communication
} 
- If the student's traffic is not communicating through one of the APs covering the room, then the device will be assigned a "Non Room network" IP;

- If the student traffic does not belong to the group to be analysed and the device in question is communicating through one of the APs covering the room, then the device will be assigned an IP from a "normal eduroam network";

In the final steps we resolved the IP's in Wireshark (software used for the capture) and the unsolved IP's where filtered in a $\mathrm{PHP}^{3}$ script, through the gethostbyaddr method where the unsolved ones are incrementally added.

Finally, using an IP list, we performed a comparison to resolve any unresolved names; This step allowed to fine tune the process and to make the final test.

\section{Analysed cases}

After performing these tests, a scenario for this final pilot was set up to validate if the data to be collected matched the outlined objectives. In this final pilot, logs were collected in a classroom so that the scenario was as close to the desired collection as possible. In this pilot, it was possible to verify that the collected data fulfilled the requirements. At this point, in addition to the HTTPS traffic packets, the packets referring to $\mathrm{DNS}^{4}$ traffic were also included. This option made the HTTPS traffic more easily understandable. Furthermore, the researcher could conclude that all authenticated devices belonged to separate accounts.

The results show that the pre-tests/pilots and the final pilot turned out very well and in a very reliable way since they allowed to verify the main problems that could occur and helped to certify that the traffic anonymity condition was respected. In fact, only the HTTPS was considered, and all other communication was encrypted with no risk of corruption of private data. Moreover, this option had an important justification: the fact that HTTPS traffic could be more easily understandable and the fact that it allowed certifying that all the authenticated devices of the wireless network belonged to separate accounts.

To process and create output visualization of the data, the choice was an integrated solution, both for the processing stage and for creating visualisations. Given the variety of tools available, several were tried out and Tableau Software ${ }^{\circ}$ (Tableau Prep ${ }^{\circ}$ and Tableau Desktop ${ }^{\circ}$ ) was chosen. Tableau Software is an interactive data processing and visualisation tool that belongs to the Salesforce company and, although it is paid software, it allows for an academic licence that was used in this project.

This solution, besides allowing working with a large amount of data, also allows for a very interactive data treatment and visualisation. This software also allows the importation of data from various sources, which in the case of this study was also an advantage.

This solution allowed us to work with large amounts of data but it also allowed for a very interactive data treatment and visualization. In the case of Tableau Prep, the file with the logs was imported in a CSV format ${ }^{5}$ and treated iteratively in a dynamic way, being refined to the desired data in a second stage. As an example, we can mention the

${ }^{3} \mathrm{PHP}$ is a general-purpose scripting language especially suited to web development

${ }^{4} \mathrm{DNS}$ is naming system for computers, services, or other resources connected to the Internet

${ }^{5}$ Unformatted file where values are separated by commas 
separation of the field "time duration" in hours, minutes and seconds fields; all the IPs were converted to a generic name "student"; all the destinations visited by the students were grouped in main categories, as for instance "Facebook", as each application had numerous distinct destinations.

About 30 changes in data treatment and in data flow "cleaning" were performed, which were, later, exported to Tableau Desktop. Each file imported to Tableau Prep, in addition to the changes applied to the previous file, was refined with more changes, in an iterative process.

After treating the data on Tableau prep the generated data flow was imported to Tableau Desktop so that dynamic data visualizations were created. At this stage, dimensions, measurements, and filters were created according to the desired data visualization. The software has the big advantage of creating dynamic visualizations of the logs' data which allows for a different and richer perspective on the data obtained, in order to deepen further studies about the same topic.

\section{Discussion and conclusions}

This paper aimed to describe the process of a pilot to carry out a larger study where we wanted to cross-reference actual usage data (logs) of mobile applications in the classroom with data from student questionnaires. In this article we also present the main results of this pilot, both from the point of view of the process of the pilot and from the point of view of the data of use of mobile applications by students in the classroom.

From the preliminary data analysis of this pilot, we can infer that the most used apps are Facebook, Google and Instagram, as we can see in Fig. 2 and Fig. 3, although some variations between the attendees of the courses were registered when it comes to other apps. For example, in the case of the Design course, there are alternative apps being used such as YouTube or Vimeo.

Another noticeable preliminary result is that students use Facebook more at the beginning of classes and Instagram is used more at the end, as we can see in Fig. 4 and Fig. 5.

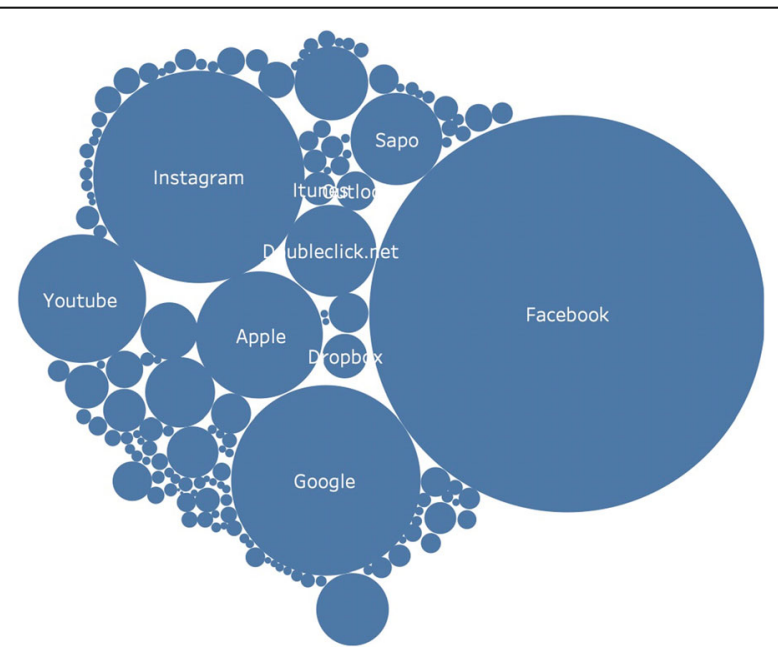

Fig. 2 General use of applications in Scriptwriting class 


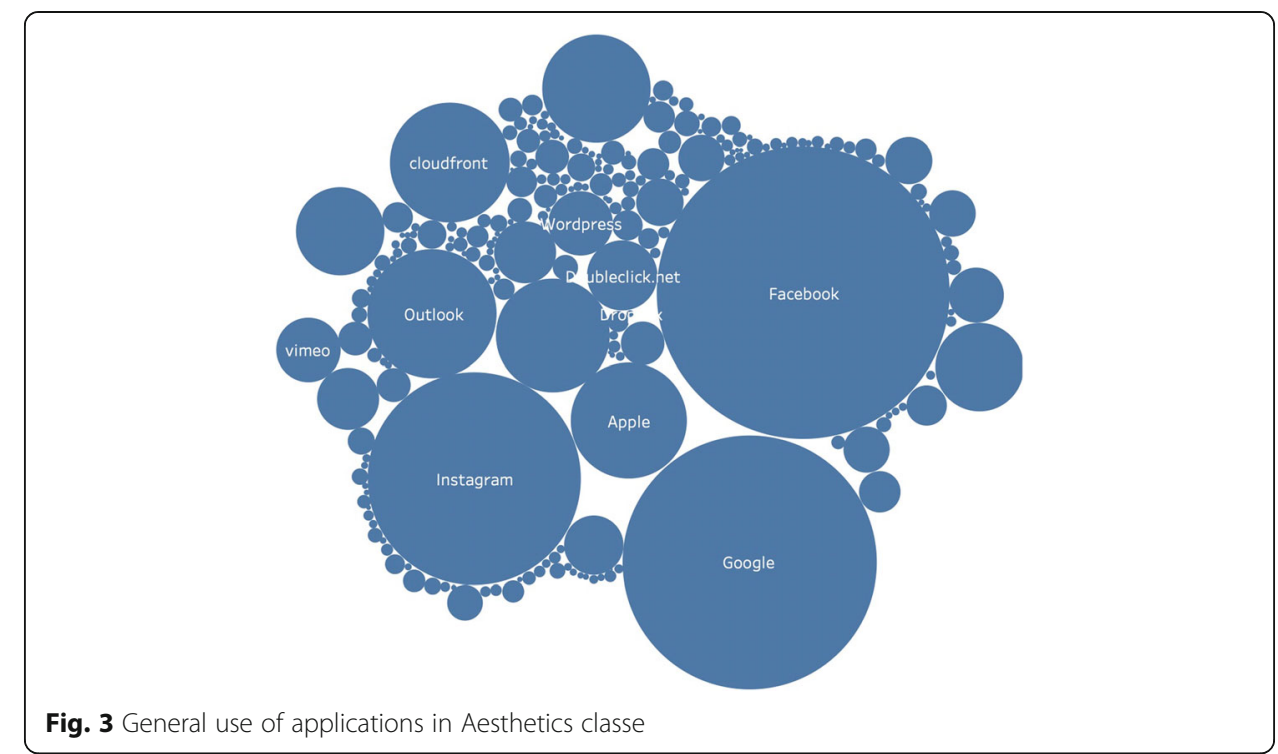

In addition, the developed model was used in the main study with a bigger convenience sampling approach, which may provide a more accurate representation of the population of mobile-phone-users in the study field.

The visualizations created in a dynamic way during this study showed that the use of logs as a complementary data provider to other instruments, such as questionnaires, can be an added value for this research field.

On the other hand, this pilot contradicts (sometimes slightly, others considerably) the results of the questionnaires answered by the students and whose logs were collected and analysed. Logs show that:

i) there is a common use of mobile applications during the classes;

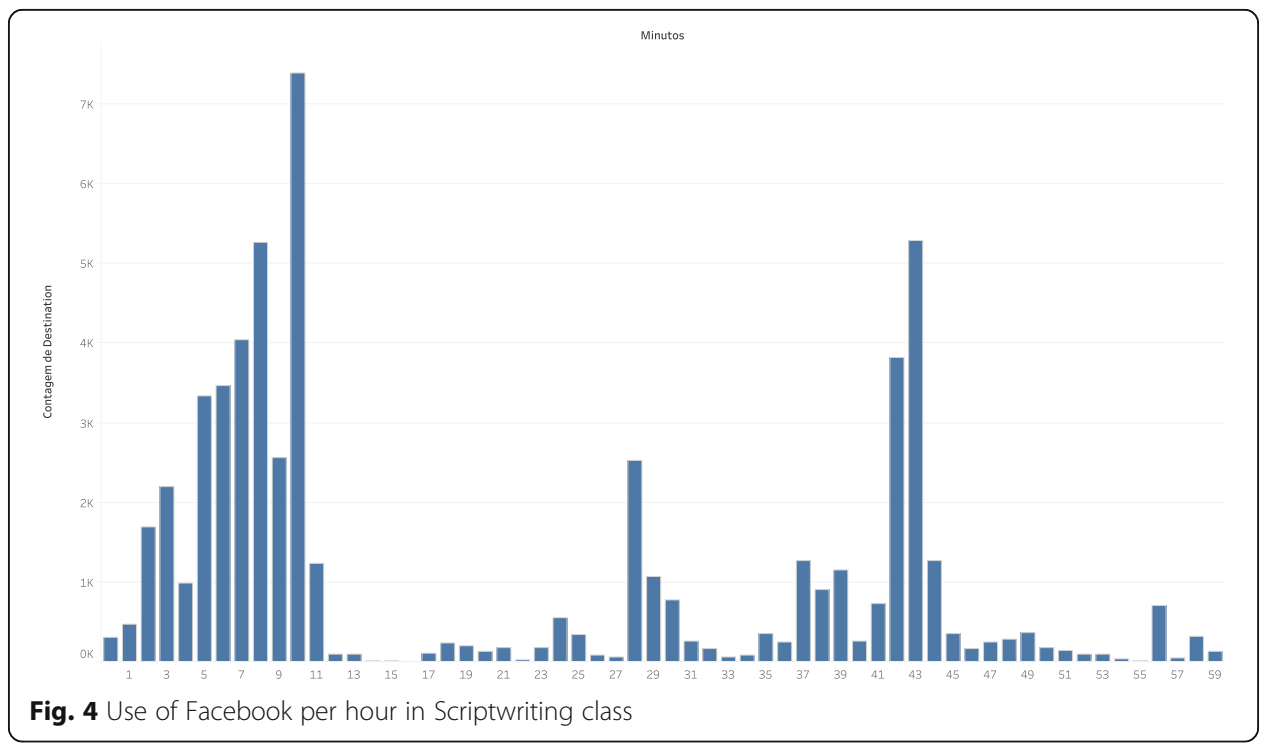




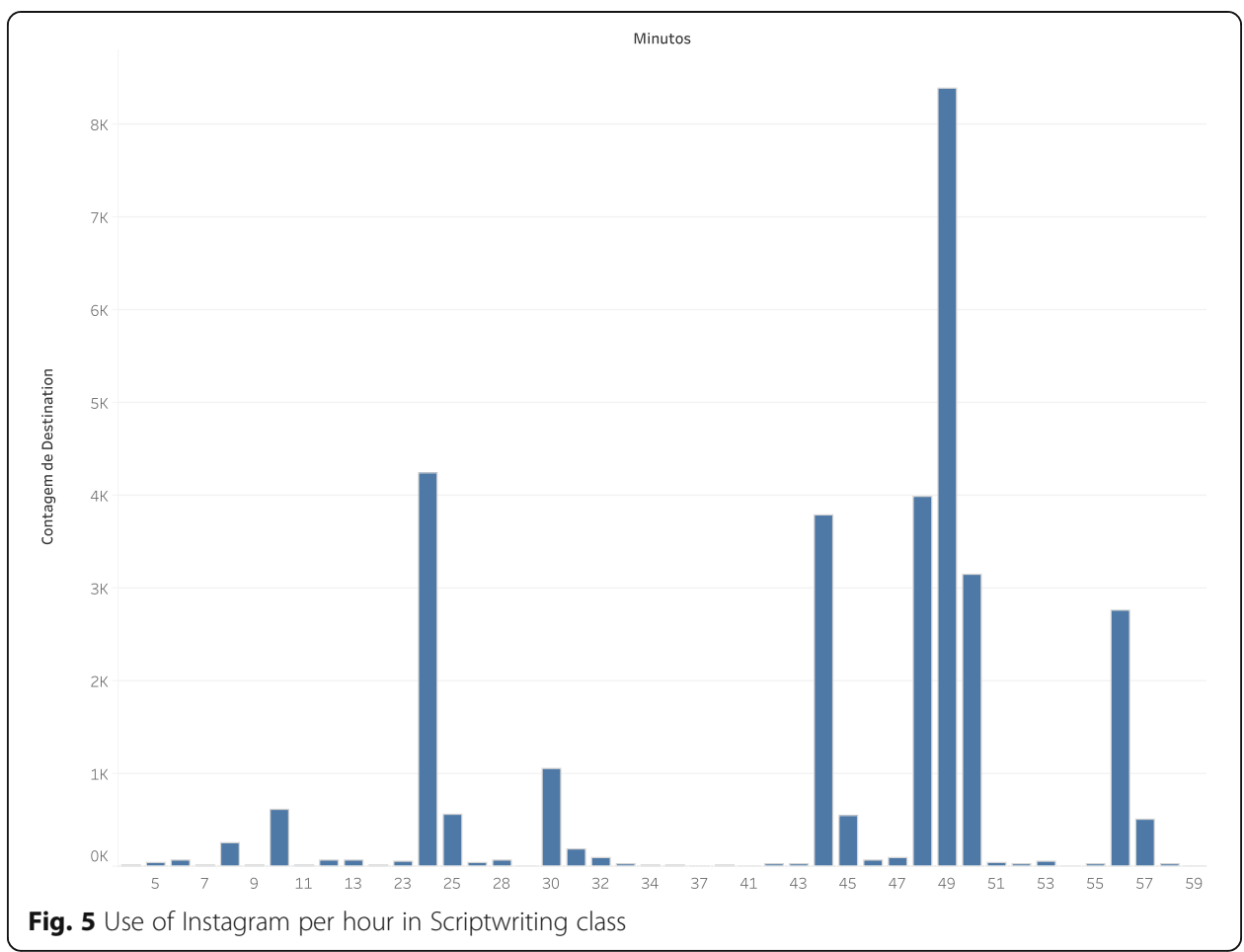

ii) the purpose of the access is different: participants report that they use mobile applications mostly for academic reasons, but it can be noted that there is a general use of other mobile applications such as social networks and Youtube;

iii) the usage time is much longer than what participants reported;

iv) the frequency is also different: students stated that they use mobile applications in classes only 1-3 days a week, but we found that, in the analysed classes, there is an almost constant use of them, and finally

v) students report that they do not use social networks much in class, but the use is, in fact, massive.

The students' perception of the "use of mobile devices and applications during lessons", and as already mentioned, during a teaching activity - $70 \%$ of the students refer using the applications between 1 to 5 times, 22\% between 6 to 10 times and 4\% more than 10 times. It should also be noted, as previously mentioned, that only $4 \%$ mention not using them. With regards to the use during the week, $56 \%$ of the students refer using them between 4 to 5 days per week and $39 \%$ between 1 to 3 days per week. There is also a relatively low percentage of students mentioning that they use the devices during class more than ten times (4\%).

However, analysis of the logs shows that this use appears to be much more intensive. We performed a calculation based on the average number of accesses, from which we removed $40 \%$ of potential automatic accesses and divided by the average number of accesses each application had in the initial test. The results present 6.6 accesses to the device per class/student in the class with the fewest accesses, and for the highest case, 313 accesses to the device per class/student. 
This result is reinforced by results from other studies, such as the Mobile Survey Report, which states that students make regular use of laptops and smartphones during lessons (Seilhamer et al., 2018).

These conclusions lead us to some very serious insights on this subject. Apparently, even older students have a misperception of their use of online applications during classes. There is a serious discrepancy and incongruency between the behaviours that they claim to adopt and those they actually engage in during the classes. There are authors, who argue for the need for other types of studies that support this type of approach (Gerpott \& Thomas, 2014), because the perception reported by users may not correspond to the actual use. It means that this gap deserves a deeper reflection. Why does it happen? Are students not motivated in higher education? Is the world offered online more interesting than the one in the physical campus? We will try to answer these questions in the main study.

\section{Abbreviations}

HEls: Higher Education Institutions; APs: Access Points; HTTPS: Hypertext Transfer Protocol Secure; IP: Internet Protocol; PHP: Hypertext Preprocessor; DNS: Domain Name System; CSV: Comma-separated values

\section{Acknowledgements}

Not applicable.

\section{Authors' contributions}

DO wrote the introduction and discussion, and saw to the article structure, wrote the method section and conducted the data analysis. LP and CS conducted the literature review. All authors contributed to the discussion and conclusion sections, and the overall flow of the article. All authors read and approved the final manuscript.

\section{Funding}

The authors declare that they have no funding in this project.

Availability of data and materials

Some of the visualizations created are publicly available at https://public.tableau.com/profile/davidoliveiraua

\section{Declarations}

Competing interests

The authors declare that they have no competing interests.

Received: 20 January 2021 Accepted: 16 July 2021

Published online: 09 August 2021

\section{References}

Aagaard, J. (2015). Drawn to distraction: A qualitative study of off-task use of educational technology, Computers \& Education, Elsevier

Alexander, B., Ashford-Rowe, K., Barajas-Murphy, N., Dobbin, G., Knott, J., McCormack, M., Pomerantz, J., Seilhamer, R., \& Weber, N. (2019). EDUCAUSE Horizon Report: 2019 Higher Education Edition. https://library.educause.edu/-/media/files/library/201 9/4/2019horizonreport.pdf?la=en\&hash=C8E8D444AF372E705FA1BF9D4FF0DD4CC6F0FDD1

Alves, A. G., Martins, C. A., Pinho, E. S., \& Tobias, G. C. (2017). A Teoria Fundamentada em dados como ferramenta de análise em pesquisa qualitativa. 6o Congresso Ibero-Americano Em Investigação Qualitativa - CIAIQ2017, 1, 499-507

Boase, J., \& Ling, R. (2013). Measuring Mobile phone use: Self-report versus log data. Journal of Computer-Mediated Communication, 18(4), 508-519 https://doi.org/10.1111/jcc4.12021.

De Reuver, M., \& Bouwman, H. (2015). Dealing with self-report bias in mobile internet acceptance and usage studies. Information Management, 52(3), 287-294 https://doi.org/10.1016/j.im.2014.12.002.

Dobbin, G., Dahlstrom, E., Arroway, P., \& Sheehan, M. C. (2011). Mobile IT in higher education. Educause, 1-33.

Gerpott, T. J. and Thomas, S. (2014) Empirical research on mobile internet usage: A meta- analysis of the literature, telecommunications policy, 38(3): 291-310. 2014. [online]. Available: http://www.sciencedirect.com/science/article/pii/S03 0859611300175 Accessed on: Dec., 20, 2016.

GMI. (2019). Mobile Learning Market Size | Global Growth Statistics 2020-2026. https://www.gminsights.com/industry-analysis/ mobile-learning-market

Jesse, G. R. (2015). Smartphone and app usage among college students: Using smartphones effectively for social and educational needs. Proceedings of the EDSIG Conference, 2015, 1-13 http://proc.iscap.info/2015/pdf/3424.pdf

Long, D. R., Strauss, A., \& Corbin, J. (1993). Basics of Qualitative Research: Grounded Theory Procedures and Techniques. The Modern Language Journal, 77(2), 235 https://doi.org/10.2307/328955 
Magda, A. J., \& Aslanian, C. B. (2018). Online college students 2018. Comprehensive Data on Demands and Preferences. https://www.learninghouse.com/knowledge-center/research-reports/ocs2018/

Monteiro, A., Bento, M., Lencastre, J., Pereira, M., Ramos, A., Osório, A. J., \& Silva, B. (2017). Challenges of mobile learning - A comparative study on use of mobile devices in six European schools: Italy, Greece, Poland, Portugal, Romania and Turkey. Revista de Estudios e Investigación En Psicología y Educación, 13, 352. https://doi.org/10.17979/reipe.2017.0.13.3229-357.

Oliveira, D., Tavares, R., \& Laranjeiro, D. (2017). Estudo de avaliação de aplicações móveis de instituições de ensino superior português. https://www.researchgate.net/publication/307981176

Parslow, R. C., Hepworth, S. J., \& McKinney, P. A. (2003). Recall of past use of mobile phone handsets. Radiat. Prot. Dosim., 106(3), pp. 233-240. http://search.ebscohost.com/login.aspx?direct=true\&db=cmedm\&AN=14690324\&site=ehost-live, DOI: https://doi.org/10.1093/oxfordjournals.rpd.a006354

Raento, M., Oulasvirta, A., \& Eagle, N. (2009). Smartphones: An emerging tool for social scientists. Sociological Methods \& Research, 37(3), 426-454 https://doi.org/10.1177/0049124108330005.

Ryu, H., \& Parsons, D. (2008). Innovative Mobile learning: Techniques and technologies. Information Science Reference Imprint of: IGI Publishing.

Seilhamer, R., Chen, B., DeNoyelles, A., Raible, J., Bauer, S., \& Salter, A. (2018). 2018 Mobile Survey Report. https://digitallearning. ucf.edu/msi/research/mobile/survey2018/

Sharples, M., Corlett, D. \& Westmancott, O. (2002). The design and implementation of a mobile learning platform based on android. Proceedings - 2013 International Conference on Information Science and Cloud Computing Companion, ISCC-C 2013, 345-350. https://doi.org/10.1109/ISCC-C.2013.136

UNESCO. (2013). Policy guidelines for mobile learning. In policy guidelines for mobile learning. https://doi.org/ISBN 978-92-3001143-7. France

Vicente, F. (2013). WelcomeUA: Desenvolvimento de interface e avaliação da usabilidade. 136. https://ria.ua.pt/handle/1 $0773 / 12403$

\section{Publisher's Note}

Springer Nature remains neutral with regard to jurisdictional claims in published maps and institutional affiliations.

\section{Submit your manuscript to a SpringerOpen ${ }^{\circ}$ journal and benefit from:}

- Convenient online submission

- Rigorous peer review

- Open access: articles freely available online

High visibility within the field

- Retaining the copyright to your article

Submit your next manuscript at $\boldsymbol{\nabla}$ springeropen.com 